Original article

\title{
Can neuropsychological testing facilitate differential diagnosis between at-risk mental state (ARMS) for psychosis and adult attention-deficit/hyperactivity disorder (ADHD)?
}

\author{
Erich Studerus ${ }^{\mathrm{a}}$, Salvatore Corbisiero ${ }^{\mathrm{b}}$, Nadine Mazzariello ${ }^{\mathrm{a}}$, Sarah Ittig ${ }^{\mathrm{a}}$, Letizia Leanza ${ }^{\mathrm{a}}$, \\ Laura Egloff ${ }^{\mathrm{a}}$, Katharina Beck ${ }^{\mathrm{a}}$, Ulrike Heitz ${ }^{\mathrm{a}}$, Christina Andreou ${ }^{\mathrm{a}}$, Rolf-Dieter Stieglitz ${ }^{\mathrm{b}, \mathrm{c}}$, \\ Anita Riecher-Rössler ${ }^{\mathrm{a}, *}$
}

a Center for Gender Research and Early Detection, University of Basel Psychiatric Hospital, Basel, Switzerland

${ }^{\mathrm{b}}$ Clinical Psychology and Psychiatry, University of Basel Psychiatric Hospital, Basel, Switzerland

${ }^{\mathrm{C}}$ University of Basel Psychiatric Hospital, Basel, Switzerland

\section{A R T I C L E I N F O}

\section{Article history:}

Received 17 January 2018

Received in revised form 27 February 2018

Accepted 28 February 2018

Available online 31 March 2018

\section{Keywords:}

ADHD

ARMS

Psychosis

Neurocognition

Differential diagnosis

\begin{abstract}
A B S T R A C T
Background: Patients with an at-risk mental state (ARMS) for psychosis and patients with attentiondeficit/hyperactivity disorder (ADHD) have many overlapping signs and symptoms and hence can be difficult to differentiate clinically. The aim of this study was to investigate whether the differential diagnosis between ARMS and adult ADHD could be improved by neuropsychological testing. Methods: 168 ARMS patients, 123 adult ADHD patients and 109 healthy controls (HC) were recruited via specialized clinics of the University of Basel Psychiatric Hospital. Sustained attention and impulsivity were tested with the Continuous Performance Test, verbal learning and memory with the California Verbal Learning Test, and problem solving abilities with the Tower of Hanoi Task. Group differences in neuropsychological performance were analyzed using generalized linear models. Furthermore, to investigate whether adult ADHD and ARMS can be correctly classified based on the pattern of cognitive deficits, machine learning (i.e. random forests) was applied.

Results: Compared to HC, both patient groups showed deficits in attention and impulsivity and verbal learning and memory. However, in adult ADHD patients the deficits were comparatively larger. Accordingly, a machine learning model predicted group membership based on the individual neurocognitive performance profile with good accuracy (AUC $=0.82$ ).

Conclusions: Our results are in line with current meta-analyses reporting that impairments in the domains of attention and verbal learning are of medium effect size in adult ADHD and of small effect size in ARMS patients and suggest that measures of these domains can be exploited to improve the differential diagnosis between adult ADHD and ARMS patients.
\end{abstract}

(C) 2018 Elsevier Masson SAS. All rights reserved.

\section{Introduction}

Young adults seeking help at psychiatric services frequently suffer from adult attention-deficit/hyperactivity disorder (ADHD) or an at-risk mental state (ARMS) for psychosis. Although the latter is not yet accepted as an official diagnosis, it is increasingly identified and treated in clinical practice for the following reasons. First, it is now well established that patients who meet ARMS criteria not only have a largely increased risk of developing psychosis, but also suffer from psychopathological symptoms and impaired psychosocial functioning requiring clinical attention [1] Second, although comorbidity with other psychiatric disorders, particularly with affective and anxiety disorders, is high [2], the specific psychopathology of ARMS patients is not adequately addressed by existing diagnostic categories [3,4]. Consequently, the European Psychiatric Association (EPA) has recently issued evidence based recommendations for the early detection [5] and treatment [6] of these patients. Furthermore, attenuated psychosis syndrome, which was defined according to the most frequent ARMS criterion, has been placed in Section 3 of the Diagnostic and

\footnotetext{
* Corresponding author at: University of Basel Psychiatric Hospital, Center for Gender Research and Early Detection, Wilhelm Klein-Strasse 27, CH-4002 Basel, Switzerland. E-mail address: anita.riecher@upkbs.ch (A. Riecher-Rössler).
} 
Statistical Manual of Mental Disorders, 5th Edition (DSM-5) [7] as a new disorder for further study.

The distinction between adult ADHD and ARMS for psychosis can be a challenging task for clinicians because these disorders have many overlapping signs and symptoms, such as difficulties concentrating, lack of attention and other cognitive deficits $[8,9]$, disorganized behavior, performance problems in school or at work, and problems with relationships [10,11]. Additionally, both disorders can present with restlessness, nervousness, irritability, hypersensitivity, sudden lack of interest, initiative, energy and drive, low frustration tolerance, as well as poor resilience to stress $[12,13]$. Furthermore, both disorders frequently occur in early adulthood and both are considered neurodevelopmental in origin $[14,15]$. Moreover, ADHD in childhood has been found to be associated with an increased risk of schizophrenia in adulthood both in prospective follow-up [16,17] and retrospective studies $[18,19]$. Likewise, individuals genetically at-risk for schizophrenia $[20,21]$ and patients with psychosis [22] have been found to more frequently demonstrate ADHD-like features than healthy controls. It has been suggested that the overlap between ADHD and psychotic disorders is due to shared genetic [23] and environmental risk factors, particularly obstetric complications [24]. Another potential explanation is that - due to their similar clinical manifestation - ADHD is a frequent misdiagnosis of early signs of psychotic disorders [17].

Missclassifying patients with an ARMS for psychosis as ADHD patients can lead to inappropriate and even potentially harmful treatment of these patients. Specifically, since ADHD is most commonly treated with stimulant drugs which exert their pharmacological effects via increasing the levels of dopamine [25], and since increased levels of synaptic dopamine are implicated in the generation of psychotic symptoms [26], treating ARMS patients as ADHD patients could potentially exacerbate (pre)psychotic symptoms in these patients [for review, see Ref. 27].

A possible way to improve differential diagnosis between these two disorders is to take the neuropsychological performance profile into account. Although current meta-analyses indicate that - compared to healthy controls (HC) - both adult ADHD and ARMS for psychosis patients show impairments across a wide range of cognitive domains, the degree and pattern of impairments seem to differ. While adult ADHD patients were found to be most strongly impaired in sustained and selective attention, inhibition, and verbal learning and memory with effect sizes in the small to medium range $[9,28,29]$. ARMS patients showed the largest impairments in speed of processing, social cognition and verbal learning with, however, mostly small effect sizes [8].

However, to our knowledge, no study has directly tested cognitive performance differences between adult ADHD and ARMS patients. Furthermore, it is currently unknown whether potential differences on the group level could be exploited to facilitate diagnostic classification on the individual level by means of automated pattern recognition or machine learning methods. This is unfortunate because neuropsychological testing is already routinely conducted in early detection services for both disorders and has shown promise in the classification between ADHD and various other psychiatric disorders, including mood and anxiety disorders [30-33], autism spectrum disorders [34], and borderline personality disorders [35], and between ARMS for psychosis and depressive disorders [36].

Thus, the aim of this study was 1 ) to directly test neuropsychological performance differences between adult ADHD, ARMS for psychosis patients, and $\mathrm{HC}$ in the domains of sustained attention and impulsivity, verbal learning and memory, and problem solving abilities and 2) to estimate the classification accuracy of machine learning model predicting group membership from all neurocognitive performance measures combined.
Based on the above mentioned meta-analyses [8,9,28,29], we hypothesized that both patient groups would show worse cognitive performance in all tested domains relative to healthy controls and that adult ADHD patients would show larger deficits than ARMS patients in the domains of attention and impulsivity and verbal learning and memory, but not problem solving abilities. Furthermore, we expected that classification between adult ADHD and ARMS patients based on all neuropsychological performance measures combined can be achieved with moderate to high accuracy.

\section{Methods}

\subsection{Study design}

In this cross-sectional study, the cognitive performance of three groups was compared: 1) patients with adult ADHD, 2) patients with an ARMS, and 3) healthy controls (HC). All participants provided their written informed consent. The study was approved by the by the local ethics committee (Ethikkommission der Nordwest- und Zentralschweiz) and conformed to the Declaration of Helsinki.

\subsection{Recruitment of patients with adult ADHD}

Patients with adult ADHD were recruited via the ADHD Special Consultations Unit of the Outpatient Department of the University of Basel Psychiatric Hospital between 2010 and 2014. All referrals to this Unit underwent an extensive ADHD screening procedure conducted by two independent experts and including a clinical interview, a self-rating and an observer-rating scale. School certificates and/or reports from teachers on behavioral problems were also considered. The procedure conformed to general standards for clinical diagnostics and followed the recommendations for the diagnostics and management of ADHD [37]. The diagnosis was not made solely on the basis of rating scales, but it also took into account a full developmental and psychiatric history. Instruments applied in the diagnostic process were the WenderReimherr Adult Attention Deficit Disorder Rating Scale (WRAADDS) [38] (German version: [39,40]) and the Conners' Adult ADHD Rating Scales (CAARS) [41]. Former symptoms in childhood were assessed systematically with the short version of the Wender Utah Rating Scale (WURS-k) [42] (German version: [43]). To check for current symptoms, a combination of the results from the clinical interview and the rating scales was used. An ADHD diagnosis was given when an individual met at least six criteria of the dimension of inattention and/or six criteria of the dimension of hyperactivity/impulsivity according to DSM-IV. Only patients who met the diagnostic criteria for ADHD and who were at least 18 years old were included into this study. Exclusion criteria were an intelligence quotient (IQ) $<85$, schizophrenia or other psychotic disorders, a current or most recent episode of a manic disorder or current severe major depressive disorder, acute stress disorder, or substance intoxication or withdrawal.

\subsection{Recruitment of patients with an ARMS for psychosis}

ARMS patients were recruited and assessed between March 1, 2000 and December 31, 2016 as part of the Basel Früherkennung von Psychosen (FePsy) study, a prospective multilevel study, which aims to improve the early detection of psychosis. A detailed description of the study design can be found elsewhere [44,45]. In brief, individuals suspected to be in their early (prodromal) phase of psychosis were referred to our specialized early detection clinic at the Outpatient Department of the Psychiatric University Hospital Basel, Switzerland. All referrals to the clinic during the 
study period were screened with the Basel Screening Instrument for Psychosis (BSIP) [46], which has been specifically designed to identify patients with an ARMS for psychosis or first episode of psychosis (FEP). Individuals were classified as being in an ARMS if they met one of the following risk criteria: (a) attenuated psychotic symptoms (APS) or brief limited intermittent psychotic symptoms (BLIPS) according to the PACE criteria [47], (b) familial aggregation of psychotic disorders in combination with at least two further risk factors similar to the PACE criteria, or (c) a minimal amount and combination of certain risk factors according to the BSIP [for details, see Ref. 46]. The BSIP has been shown to have a good interrater reliability $(\kappa=0.67)$ for the assessment of the ARMS and a high predictive validity [46]. Exclusion criteria were: age $<18$ years, insufficient knowledge of German, IQ below 85 , previous episode of schizophrenic psychosis, psychosis clearly due to organic reasons or substance abuse, or psychotic symptomatology within a clearly diagnosed affective psychosis or borderline personality disorder. Patients who were treated with antipsychotics $>3$ weeks or who had exceeded a $2500 \mathrm{mg}$ cumulative chlorpromazine equivalent dose were also excluded.

\subsection{Recruitment of healthy controls (HC)}

HC were also recruited and assessed as part of the FePsy study. They were recruited from trade schools, hospital staff and through advertisements. Subjects were excluded if they had a current or former psychiatric disorder or neurological disease, serious medical condition, substance abuse, or a family history of psychiatric disorder.

\subsection{Neuropsychological assessment}

Patients with adult ADHD were assessed at the ADHD Special Consultations Unit and patients with an ARMS for psychosis and $\mathrm{HC}$ were assessed at the early detection of psychosis clinic with neuropsychological test batteries that were overlapping in the following tests: 1) Continuous Performance Test (CPT) [48], 2) California Verbal Learning Test (CVLT) [49] and 3) the computer administered Tower of Hanoi (ToH) [50]. A detailed description of these tests is provided in the online Supplementary material.

\subsection{Statistical analysis}

All data were analyzed using the $\mathrm{R}$ language and environment for statistical computing [51]. For testing differences between adult ADHD, ARMS and HC groups on sociodemographic variables, Pearson's $\chi^{2}$-tests and analysis of variance (ANOVA) were used for categorical and continuous variables, respectively.

Group differences in neuropsychological performance measures were analyzed using generalized linear models (GLM). GLMs are flexible generalizations of the ordinary linear regression, which differ from them in two major aspects: First, the distribution of the response variable can be non-normal and/or non-continuous (e.g., it can be binary, ordered categorical, a count etc.). Second, the dependent variable values are predicted from a linear combination of predictor variables, which are connected to the dependent variable via a link function (e.g. logit, log, inverse etc.). Thus, GLMs can take advantage of the specific structure of each variable and respect natural boundaries and distributions of variables when making predictions [for applied examples of GLMs with neuropsychological data, see Refs. 52,53].

For the number of omissions and commissions in the CPT, we used negative binomial models with log-link function because these are count variables (i.e. only non-negative integer values are possible). We used negative binomial instead of standard Poisson regression for these measures because it allowed handling overdispersion [54]. For CVLT performance measures, we used binomial models with logit link function, because each measure quantified the number of words that were remembered from one or several lists of words with fixed length. For the reaction time in the CPT and the number of moves and time to complete in the $\mathrm{ToH}$ Gamma regression models with an inverse link function were a natural choice because these variables were non-negative and right-skewed.

To control for confounding effects, all GLMs included sex and age as covariates. We first tested for overall group differences using likelihood ratio tests and then performed all possible pairwise comparisons using the ghlt function in the $\mathrm{R}$ multcomp package [55]. P-values were adjusted for multiple testing using the Benjamini-Hochberg procedure [56] both across all pairwise group comparisons and neurocognitive variables.

To find out whether all neurocognitive performance measures combined can successfully discriminate between ARMS and ADHD patients on an individual level, we additionally analyzed our data with a supervised machine learning method. Specifically, a random forest model was trained and tested that predicted group membership based on the individual performance across all neurocognitive variables. We chose the random forest algorithm because it can automatically 1) accommodate nonlinear relationships between predictor and outcome variables, 2) capture complex interactions between predictors and 3) deal with highly correlated predictors, outliers and missing data [57]. Furthermore, it has been shown to achieve excellent predictive accuracy over a wide of range predictive tasks even without hyperparameter tuning [58]. To eliminate the influence of age and sex, we first created two equally sized samples of ADHD and ARMS patients that were matched on age and sex using propensity score matching as implemented in the matching package for $\mathrm{R}$ [59]. Next, a random forest model for binary outcomes was trained and tested using 10 -fold cross validation with 10 repetitions. The discriminative ability of the model was assessed with the cross-validated area under the receiver operating characteristic curve (AUC), as well as sensitivity and specificity. Model fitting and performance evaluation was conducted with the $\mathrm{R}$ packages randomForest [60] and $\mathrm{mlr}$ [61], respectively. We additionally assessed the predictive importance of each variable by looking at how much the accuracy decreased when the variable was randomly permuted using the importance function in package randomForest [60].

\section{Results}

\subsection{Sample description}

During the above described study periods, 123 adult ADHD patients, 168 ARMS patients, and 109 HC fulfilled inclusion criteria and had completed at least one of the above described neuropsychological tests. Eleven HC and 23 ARMS patients had to be excluded from the current study due to completely missing neuropsychological assessment. The excluded patients did not differ from the included patients with regard to sociodemographic characteristics. The ADHD, ARMS and HC groups did not differ with regard to gender ratios. However, adult ADHD patients were significantly older than ARMS patients and HC (see Table 1 for socio-demographic sample characteristics).

\subsection{Group differences in neuropsychological performance}

Standardized mean differences in neuropsychological performance from HC for the ARMS and ADHD groups are displayed in Fig. 1. Means and SDs, as well as p-values for tests of overall and pairwise group differences are provided in Table 2. 
Table 1

Socio-demographic sample characteristics.

\begin{tabular}{lllll}
\hline & HC & ARMS & ADHD & $p$-value \\
& $\mathrm{N}=109$ & $\mathrm{~N}=168$ & $\mathrm{~N}=122$ & \\
\hline Age & $25.0(5.28)$ & $25.4(7.23)$ & $31.6(9.83)$ & $<0.001$ \\
Gender: & & & 0.072 \\
$\quad$ Women & $47(43.1 \%)$ & $50(29.8 \%)$ & $45(36.9 \%)$ & \\
$\quad$ Men & $62(56.9 \%)$ & $118(70.2 \%)$ & $77(63.1 \%)$ & \\
Risk group: & & $91(54.2 \%)$ & & \\
$\quad$ Prepsychotic only & & $16(9.52 \%)$ & & \\
$\quad$ Genetic risk only & $25(14.9 \%)$ & & \\
$\quad$ Mixed prepsychotic & & & & \\
$\quad$ +genetic & $36(21.4 \%)$ & & \\
$\quad$ Unspecific only & & & $4(3.28 \%)$ & \\
Typ: & & & $118(96.7 \%)$ & \\
$\quad$ Inattentive type & & & \\
$\quad$ Combined type & & $47(28.0 \%)$ & $26(21.3 \%)$ & 0.249 \\
Antidepressants currently & $29(17.3 \%)$ & $8(6.56 \%)$ & 0.012 \\
Anxiolytics currently & $15(8.93 \%)$ & $9(7.38 \%)$ & 0.797 \\
Antipsychotics currently & $0(0.0 \%)$ & $11(9.02 \%)$ & $<0.001$ \\
Stimulants currently & & & \\
\hline
\end{tabular}

$\mathrm{HC}=$ healthy controls; ARMS = at-risk mental state for psychosis; ADHD = attentiondeficit/hyperactivity disorder.

When adjusted for the influence age and sex and corrected for multiple comparisons, there were overall group differences in all tested neuropsychological variables, except for the number of moves in the 5 disc ToH. Pairwise group comparisons revealed that ADHD patients showed a significantly worse performance than HC in all CPT and CVLT measures, but not in any ToH measure. ARMS patients also performed worse than $\mathrm{HC}$ in all performance scores, except for List 1, Trial 1 recall and Long Delay False Alarms in the
CVLT and number of moves in the 5 disc ToH. Finally, ADHD patients performed significantly worse than ARMS patients in all measures except the two ToH measures. Repeating the analyses without covariate adjustment did not change results except that ARMS patients additionally showed a significantly worse performance than HC in List 1 , Trial 1 recall of the CVLT ( $p=0.049)$. As can be seen in Fig. 1, cognitive impairments were mostly of medium effect sizes in adult ADHD patients and of small effect sizes in ARMS patients (see Fig. 1).

\subsection{Discrimination between ARMS and ADHD patients using machine learning}

The propensity score matching procedure selected two subgroups of ADHD and ARMS each consisting of 101 participants. The two subgroups were no longer significantly different with regard to age (ADHD: $29.0 \pm 8.2$ years, ARMS: $28.3 \pm 7.9$ years) and sex (ADHD: 34.7\% Women; ARMS: 34.7\% Women). The random forest algorithm was able to discriminate the two matched groups with relatively high accuracy based on all neurocognitive variables combined (cross-validated AUC $=0.82$, balanced accuracy $=0.75$, sensitivity $=0.73$, and specificity $=0.77$ ). The variable importance assessment revealed that CVLT long delay free recall, CPT reaction time, and CVLT recognition hits were the most important predictor variables for discriminating ADHD from ARMS patients (see Fig. 2).

\section{Discussion}

To our knowledge, this is the first study aiming to discriminate adult ADHD from ARMS for psychosis patients based on

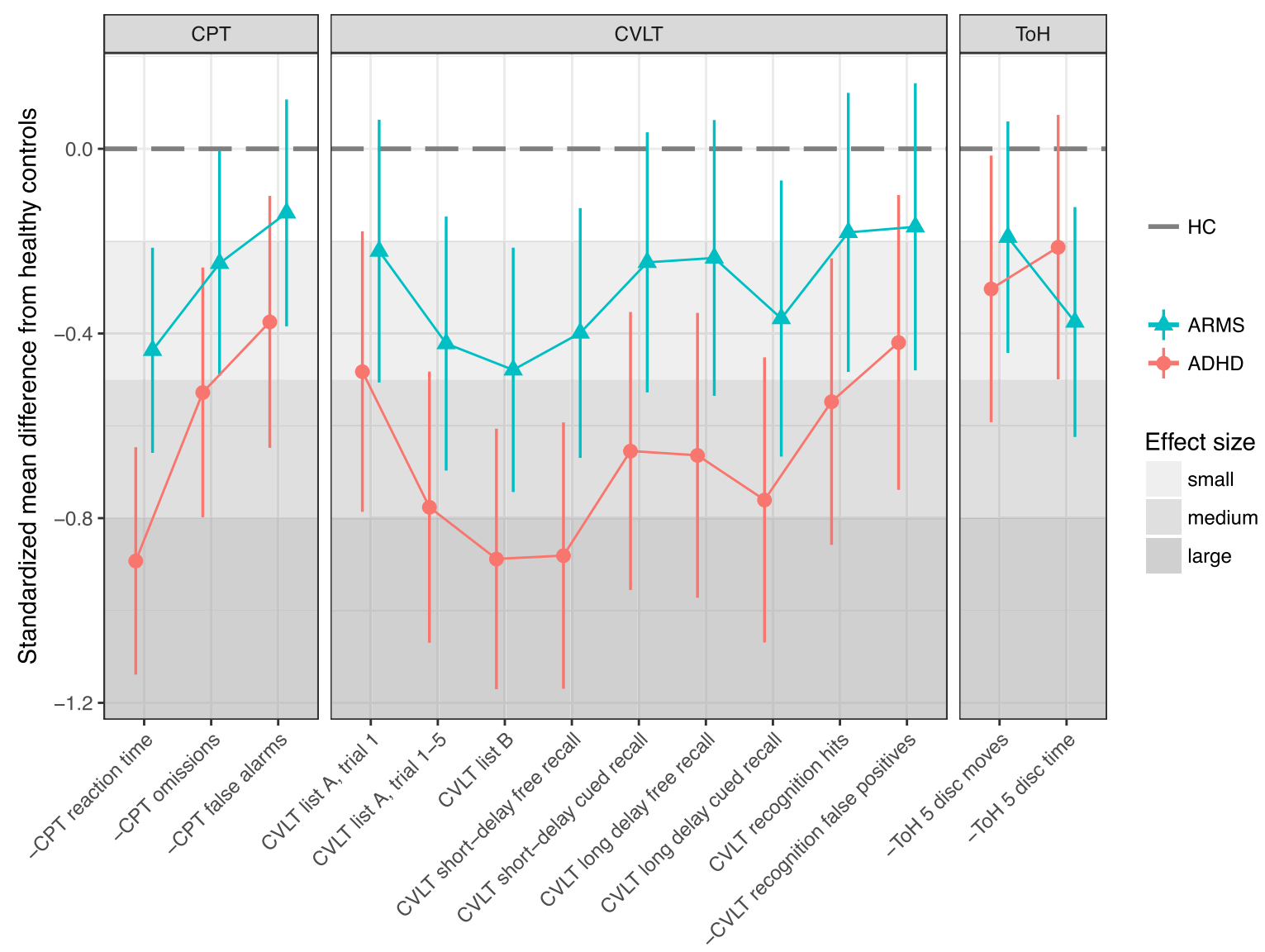

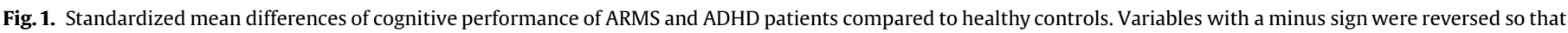
higher scores always represent better performance. Differences are adjusted for the influence of age and gender. 
Table 2

Cognitive performance of ADHD and ARMS patients

\begin{tabular}{|c|c|c|c|c|c|c|c|c|c|c|c|c|c|c|}
\hline \multirow[t]{2}{*}{ Variable } & \multicolumn{3}{|l|}{$\mathrm{HC}$} & \multicolumn{3}{|l|}{ ARMS } & \multicolumn{3}{|l|}{ ADHD } & \multirow[t]{2}{*}{ Model } & \multirow[t]{2}{*}{$p$-value overall } & \multirow{2}{*}{$\begin{array}{l}p \text {-value } \\
\text { ARMS } \\
\text { vs. HC }\end{array}$} & \multirow{2}{*}{$\begin{array}{l}p \text {-value } \\
\text { ADHD } \\
\text { vs. HC }\end{array}$} & \multirow{2}{*}{$\begin{array}{l}p \text {-value } \\
\text { ADHD } \\
\text { vs. ARMS }\end{array}$} \\
\hline & mean & SD & $n$ & mean & SD & $n$ & mean & SD & $n$ & & & & & \\
\hline \multicolumn{15}{|l|}{ CPT } \\
\hline False alarms & 1.1 & 2.2 & 108 & 2.0 & 3.3 & 155 & 3.8 & 12.3 & 120 & negative binomial & $<0.001^{* * *}$ & $0.013^{*}$ & $<0.001^{* * *}$ & $0.005^{* *}$ \\
\hline Omissions & 0.4 & 0.8 & 108 & 1.1 & 2.9 & 155 & 1.9 & 4.4 & 120 & negative binomial & $<0.001^{* * *}$ & $<0.001^{* * *}$ & $<0.001^{* * *}$ & $0.048^{*}$ \\
\hline $\begin{array}{l}\text { Reaction time } \\
\text { CVLT }\end{array}$ & 391.3 & 82.7 & 108 & 449.5 & 133.0 & 154 & 531.0 & 137.4 & 120 & Gamma & $<0.001^{* * * *}$ & $<0.001^{* * * *}$ & $<0.001^{* * *}$ & $<0.001^{* * * *}$ \\
\hline Sum of Trials $1-5$ & 62.1 & 7.7 & 68 & 56.9 & 11.7 & 142 & 53.1 & 10.8 & 121 & binomial & $<0.001^{* * *}$ & $<0.001^{* * *}$ & $<0.001^{* * *}$ & $<0.001^{* * *}$ \\
\hline List A, Trial 1 & 8.2 & 2.1 & 68 & 7.6 & 2.4 & 142 & 7.0 & 2.3 & 121 & binomial & $0.002^{* *}$ & 0.087 & $0.001^{* *}$ & $0.040^{*}$ \\
\hline Short Delay Free Recall & 13.8 & 1.9 & 68 & 12.5 & 2.9 & 141 & 11.1 & 3.0 & 121 & binomial & $<0.001^{* * *}$ & $<0.001^{* * *}$ & $<0.001^{* * *}$ & $<0.001^{* * *}$ \\
\hline Short Delay Cued Recall & 13.7 & 2.0 & 68 & 13.0 & 2.6 & 141 & 12.0 & 2.9 & 120 & binomial & $<0.001^{* * *}$ & $0.005^{* *}$ & $<0.001^{* * *}$ & $<0.001^{* * *}$ \\
\hline Long Delay Free Recall & 13.9 & 2.0 & 61 & 13.1 & 3.0 & 119 & 11.9 & 2.7 & 120 & binomial & $<0.001^{* * *}$ & $<0.001^{* * *}$ & $<0.001^{* * *}$ & $<0.001^{* * *}$ \\
\hline Long Delay Cued Recall & 14.3 & 1.7 & 61 & 13.1 & 3.0 & 119 & 12.2 & 2.7 & 120 & binomial & $<0.001^{* * * *}$ & $<0.001^{* * * *}$ & $<0.001^{* * *}$ & $<0.001^{* * *}$ \\
\hline List $B$, Trial 1 & 8.0 & 2.2 & 68 & 6.7 & 2.4 & 141 & 5.5 & 2.3 & 121 & binomial & $<0.001^{* * *}$ & $<0.001^{* * *}$ & $<0.001^{* * *}$ & $<0.001^{* * *}$ \\
\hline Long Delay False Alarms & 0.1 & 0.3 & 61 & 0.3 & 0.9 & 117 & 0.5 & 1.1 & 121 & binomial & $<0.001^{* * *}$ & 0.059 & $0.001^{* *}$ & $0.022^{*}$ \\
\hline Long Delay Recognition & 15.7 & 0.5 & 61 & 15.5 & 1.3 & 117 & 14.9 & 1.5 & 121 & binomial & $<0.001^{* * *}$ & $0.024^{*}$ & $<0.001^{* * *}$ & $<0.001^{* * *}$ \\
\hline \multicolumn{15}{|l|}{$\mathrm{ToH}$} \\
\hline Time to complete (5 disc) & 203.7 & 141.5 & 107 & 261.2 & 161.3 & 148 & 248.6 & 179.6 & 102 & Gamma & $0.011^{*}$ & $0.013^{*}$ & 0.162 & 0.269 \\
\hline Number of moves ( 5 disc) & 52.1 & 22.3 & 107 & 56.1 & 22.2 & 149 & 57.4 & 22.2 & 102 & Gamma & 0.100 & 0.194 & 0.121 & 0.421 \\
\hline
\end{tabular}

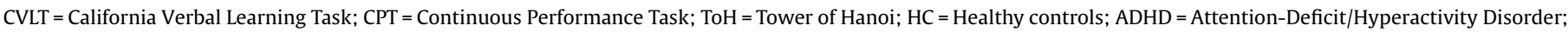
ARMS $=$ At-risk mental state for psychosis

All group comparisons are adjusted for the influence of sex and age and corrected for multiple testing using the Benjamini-Hochberg procedure

${ }^{*} p<0.05$.

** $p<0.01$.

$p<0.001$.

neuropsychological performance. In line with our hypotheses, we could demonstrate that both patient groups show significantly worse cognitive performance than $\mathrm{HC}$ in the domains of sustained attention and impulsivity and verbal learning and memory and that adult ADHD patients show larger deficits in these domains than ARMS patients. Accordingly, we could demonstrate that a machine learning algorithm (i.e. random forest) can predict group membership (ADHD vs. ARMS) with relatively high accuracy solely based on the individual pattern of cognitive deficits.

Our findings of small to medium sized cognitive deficits in adult ADHD patients are largely consistent with the most recent metaanalyses on cognitive deficits in adult ADHD patients [9,28,29]. Furthermore, our results confirmed that deficits of attention in general and sustained attention in particular, as measured by the CPT, represent one of the core features of ADHD. However, in contrast to the most recent meta-analysis of the CPT [28], which reported the strongest effect sizes for the number of omissions and commissions and no statistically significant impairment with regard to reaction times, we observed significant impairments in all performance scores of the CPT, with reaction time being the most strongly impaired. This difference might be explained by the fact that the most commonly used CPT version, the Conner's CPT [41], has $90 \%$ target trials with responses required for any letter except "X", whereas the CPT version used in this study has only $25 \%$ target trials with responses required whenever an "O" is followed by an "X". Our results also support a recent meta-analysis on memory performance in adult ADHD patients, which found that these patients show moderate impairments in verbal learning and memory resulting from deficits in memory acquisition, but not retrieval problems [29].

The cognitive performance deficits that we found in our sample of ARMS patients are also largely consistent with those reported in recent meta-analyses [8,62], which have detected impairments of mostly small effects sizes in the domains of sustained attention, verbal learning and memory and executive functions.

In accordance with our hypothesis and reported effect sizes of meta-analyses on adult ADHD [9,28,29] and ARMS patients [8,62], we could demonstrate that adult ADHD patients are significantly more impaired than ARMS patients in the domains sustained attention and impulsivity and verbal learning and memory, but not in problem solving abilities. Furthermore, we could show that these differences on the group level can be exploited to make meaningful prediction on the individual level. Specifically, by applying a machine learning algorithm to all neurocognitive variables combined we were able to discriminate ADHD from ARMS patients with a cross-validated sensitivity of 0.73 and specificity of 0.77 . Thus, our results clearly support the notion that neuropsychological testing could facilitate the differential diagnosis between these two disorders. However, it should be noted that our results do not indicate that the pattern of cognitive deficits alone could predict the correct diagnosis with sufficient certainty, only that it could provide important hints when combined with other signs and symptoms.

\subsection{Strengths and limitations}

A limitation of this study is that adult ADHD and ARMS patients were recruited from two different psychiatric services, albeit in the same psychiatric university hospital and across a similar time period. Thus, differences in neuropsychological performance could only be tested in the three cognitive tasks that were overlapping across the two services. Consequently, other important cognitive domains, such as figural memory, verbal fluency, speed of processing, and social cognition could not be investigated. Another limitation is that ADHD patients were not assessed with the BSIP for being in an ARMS for psychosis. Hence, we cannot rule out the possibility that at least some patients would fulfill criteria for both disorders. Lastly, the generalization of our results is limited by the fact that women and patients diagnosed with the inattentive subtype of ADHD were underrepresented in our sample of adult ADHD patients.

Strengths of our study are the relatively large sample sizes and the fact that relatively few patients in both patient groups were treated with medication (see Table 1). Thus, only few ADHD patients were treated with methylphenidate, which has been shown to improve performance in the CPT and other cognitive tasks in adult ADHD patients [63]. Likewise, only few ARMS and 


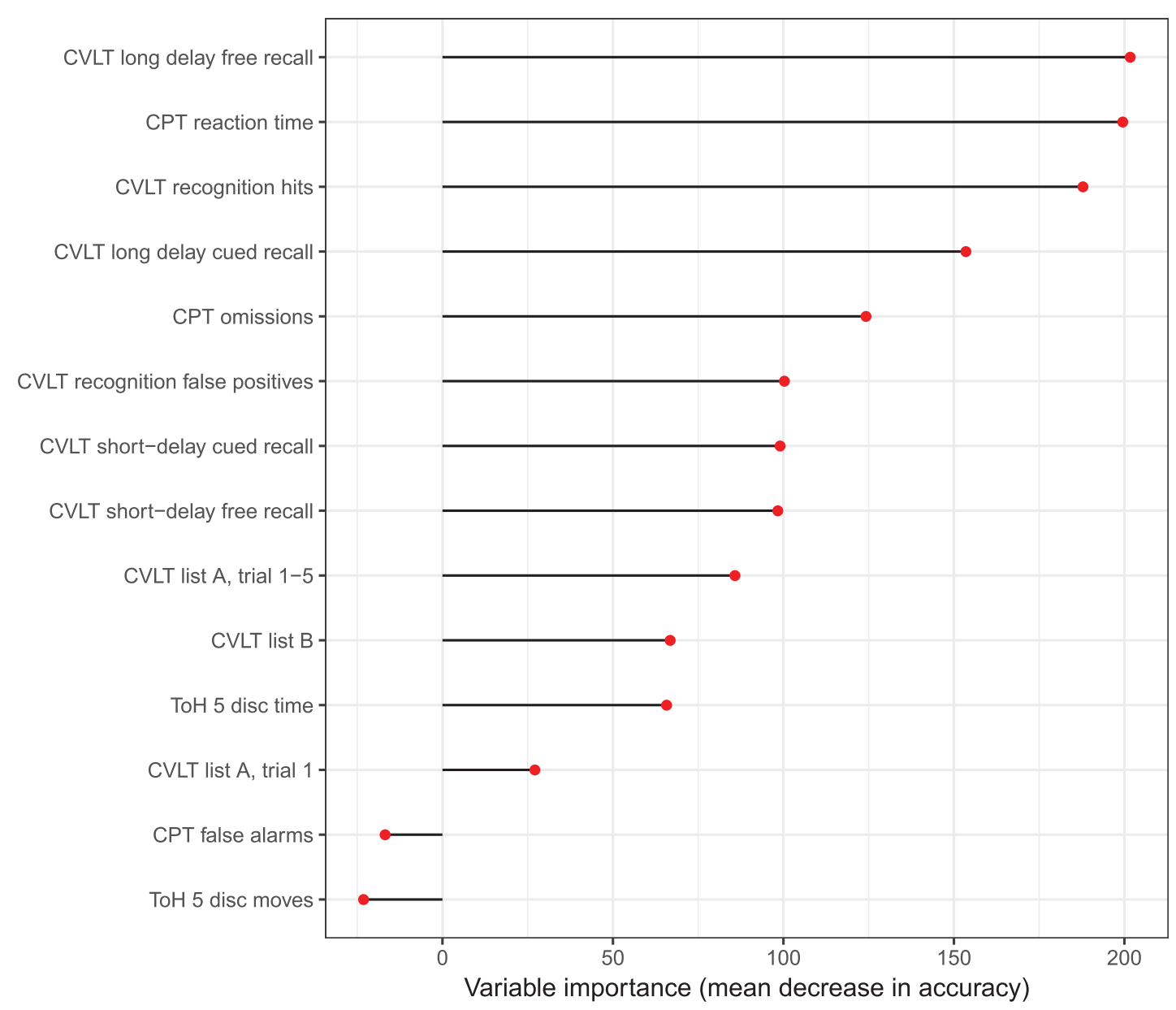

Fig. 2. Variable importance for predicting group membership (ARMS vs. ADHD) with random forest.

adult ADHD patients were treated with antipsychotics, which have been shown to negatively affect cognition, particularly speed of processing [64].

\subsection{Conclusions}

The results of this study suggest that neuropsychological testing, particularly of the domains of sustained attention and impulsivity and verbal learning and memory, can help to improve the differential diagnosis between adult ADHD and ARMS for psychosis. Future studies should replicate and extend our findings with larger samples, and more comprehensive neuropsychological test batteries.

\section{Declarations of interest}

None.

\section{Acknowledgments}

The authors thank all study participants and the referring specialists. The authors also would like to thank Claudine Pfister for her help with the preparation and submission of the manuscript.

\section{Appendix A. Supplementary data}

Supplementary data associated with this article can be found, in the online version, at https://doi.org/10.1016/j.eurpsy.2018.02.006.

\section{References}

[1] Ruhrmann S., Schultze-Lutter F, Klosterkötter J. Probably at-risk, but certainly ill-advocating the introduction of a psychosis spectrum disorder in DSM-V. Schizophr Res 2010;120:23-37.

[2] Fusar-Poli P, Nelson B, Valmaggia L, Yung AR, McGuire PK. Comorbid depressive and anxiety disorders in 509 individuals with an at-risk mental state: impact on psychopathology and transition to psychosis. Schizophr Bull 2014;40:120-31.

[3] Carpenter WT, Regier D. Diagnostic categories: provisional, not otherwise classified, or place-holder? Schizophr Bull 2016;42:1305-6.

[4] Fusar-Poli P, Carpenter WT, Woods SW, McGlashan TH. Attenuated psychosis syndrome: ready for DSM-5.1? Annu Rev Clin Psychol 2014;10:155-92.

[5] Schultze-Lutter F, Michel C, Schmidt SJ, Schimmelmann BG, Maric NP Salokangas RK, et al. EPA guidance on the early detection of clinical high risk states of psychoses. Eur Psychiatry 2015;30:405-16.

[6] Schmidt SJ, Schultze-Lutter F, Schimmelmann BG, Maric NP, Salokangas RK, Riecher-Rössler A, et al. EPA guidance on the early intervention in clinical high risk states of psychoses. Eur Psychiatry 2015;30:388-404.

[7] American Psychiatric Association. Diagnostic and statistical manual of mental disorders (DSM-5 ${ }^{\circledR}$ ). American Psychiatric Pub; 2013.

[8] Hauser M, Zhang JP, Sheridan EM, Burdick KE, Mogil R, Kane JM, et al. Neuropsychological test performance to enhance identification of subjects at clinical high risk for psychosis and to be most promising for predictive algorithms for conversion to psychosis: a meta-analysis. J Clin Psychiatry 2017;78:e28-40.

[9] Balint S, Czobor P, Komlosi S, Meszaros A, Simon V, Bitter I. Attention deficit hyperactivity disorder (ADHD): gender- and age-related differences in neurocognition. Psychol Med 2009;39:1337-45.

[10] Fusar-Poli P, Rocchetti M, Sardella A, Avila A, Brandizzi M, Caverzasi E, et al. Disorder, not just state of risk: meta-analysis of functioning and quality of life in people at high risk of psychosis. Br J Psychiatry J Ment Sci 2015;207:198206.

[11] Nijmeijer JS, Minderaa RB, Buitelaar JK, Mulligan A, Hartman CA, Hoekstra PJ. Attention-deficit/hyperactivity disorder and social dysfunctioning. Clin Psychol Rev 2008;28:692-708. 
[12] Levy E, Traicu A, Iyer S, Malla A, Joober R. Psychotic disorders comorbid with attention-deficit hyperactivity disorder: an important knowledge gap. Can J Psychiatry Revue canadienne de psychiatrie 2015;60:S48-52.

[13] Corbisiero S, Riecher-Rossler A, Buchli-Kammermann J, Stieglitz RD. Symptom overlap and screening for symptoms of attention-deficit/hyperactivity disorder and psychosis risk in help-Seeking psychiatric patients. Front Psychiatry 2017;8:206.

[14] Spencer TJ, Biederman J, Mick E. Attention-deficit/hyperactivity disorder: diagnosis, lifespan, comorbidities, and neurobiology. J Pediatr Psychol 2007;32:631-42.

[15] Owen MJ, O'Donovan MC, Thapar A, Craddock N. Neurodevelopmental hypothesis of schizophrenia. Br J Psychiatry J Ment Sci 2011;198:173-5.

[16] Dalsgaard S, Mortensen PB, Frydenberg M, Maibing CM, Nordentoft M, Thomsen PH. Association between Attention-Deficit Hyperactivity Disorder in childhood and schizophrenia later in adulthood. Eur Psychiatry 2014;29:259-63.

[17] Shyu YC, Yuan SS, Lee SY, Yang CJ, Yang KC, Lee TL, et al. Attention-deficit/ hyperactivity disorder, methylphenidate use and the risk of developing schizophrenia spectrum disorders: a nationwide population-based study in Taiwan. Schizophr Res 2015;168:161-7.

[18] Rubino IA, Frank E, Croce Nanni R, Pozzi D, Lanza di Scalea T, Siracusano A. A comparative study of axis I antecedents before age 18 of unipolar depression, bipolar disorder and schizophrenia. Psychopathology 2009;42:325-32.

[19] Rho A, Traicu A, Lepage M, Iyer SN, Malla A, Joober R. Clinical and functional implications of a history of childhood ADHD in first-episode psychosis. Schizophr Res 2015;165:128-33.

[20] Keshavan M, Montrose DM, Rajarethinam R, Diwadkar V, Prasad K, Sweeney JA. Psychopathology among offspring of parents with schizophrenia: relationship to premorbid impairments. Schizophr Res 2008;103:114-20.

[21] Keshavan MS, Sujata M, Mehra A, Montrose DM, Sweeney JA. Psychosis proneness and ADHD in young relatives of schizophrenia patients. Schizophr Res 2003:59:85-92.

[22] Karatekin C, White T, Bingham C. Shared and nonshared symptoms in youthonset psychosis and ADHD. J Atten Disord 2010;14:121-31.

[23] Hamshere ML, Stergiakouli E, Langley K, Martin J, Holmans P, Kent L, et al. Shared polygenic contribution between childhood attention-deficit hyperactivity disorder and adult schizophrenia. Br J Psychiatry J Ment Sci 2013;203:107-11.

[24] Peralta V, de Jalon EG, Campos MS, Zandio M, Sanchez-Torres A, Cuesta MJ. The meaning of childhood attention-deficit hyperactivity symptoms in patients with a first-episode of schizophrenia-spectrum psychosis. Schizophr Res 2011;126:28-35.

[25] Arnsten AF. Stimulants: therapeutic actions in ADHD. Neuropsychopharmacolgy 2006; $31: 2376-83$

[26] Howes OD, Kambeitz J, Kim E, Stahl D, Slifstein M, Abi-Dargham A, et al. The nature of dopamine dysfunction in schizophrenia and what this means for treatment. Arch Gen Psychiatry 2012;69:776-86.

[27] Kraemer M, Uekermann J, Wiltfang J, Kis B. Methylphenidate-induced psychosis in adult attention-deficit/hyperactivity disorder: report of 3 new cases and review of the literature. Clin Neuropharmacol 2010:33:204-6.

[28] Mowinckel AM, Pedersen ML, Eilertsen E, Biele G. A meta-analysis of decisionmaking and attention in adults with ADHD. J Atten Disord 2015;19:355-67.

[29] Skodzik T, Holling H, Pedersen A. Long-term memory performance in adult ADHD. J Atten Disord 2017;21:267-83.

[30] Fasmer OB, Mjeldheim K, Forland W, Hansen AL, Syrstad VE, Oedegaard KJ, et al. Linear and non-linear analyses of Conner's Continuous Performance TestII discriminate adult patients with attention deficit hyperactivity disorder from patients with mood and anxiety disorders. BMC Psychiatry 2016;16:284.

[31] Knouse LE, Barkley RA, Murphy KR. Does executive functioning (EF) predict depression in clinic-referred adults: EF tests vs. rating scales. J Affect Disord $2013 ; 145: 270-5$

[32] Solanto MV, Etefia K, Marks DJ. The utility of self-report measures and the continuous performance test in the diagnosis of ADHD in adults. CNS Spectr 20049: 649.

[33] Holst Y, Thorell LB. Neuropsychological functioning in adults with ADHD and adults with other psychiatric disorders. J Atten Disord 2017;21:137-48.

[34] Groom MJ, Young Z, Hall CL, Gillott A, Hollis C. The incremental validity of a computerised assessment added to clinical rating scales to differentiate adult ADHD from autism spectrum disorder. Psychiatry Res 2016;243:168-73.

[35] van Dijk F, Schellekens A, van den Broek P, Kan C, Verkes RJ, Buitelaar J. Do cognitive measures of response inhibition differentiate between attention deficit/hyperactivity disorder and borderline personality disorder. Psychiatry Res 2014;215:733-9.

[36] Schulze C, Zimmermann R, Gschwandtner U, Pflueger MO, Rapp C, Studerus E, et al. Can cognitive deficits facilitate differential diagnosis between at-risk mental state for psychosis and depressive disorders. Early Intervent Psychiatry 2013;7:381-90.
[37] National Institute for Health and Clinical Excellence. Attention deficit hyperactivity disorder: diagnosis and management of ADHD adhdin children, young people and adults. London: National Collaborating Centre for Mental Health; 2008.

[38] Wender PH. Attention deficit hyperactivity disorder in adults. New York: Oxford University Press; 1995.

[39] Corbisiero S, Buchli-Kammermann J, Stieglitz RD. Reliability and validity of the Wender-Reimherr-Interview (WRI) - an instrument for the diagnostic of the ADHD in adulthood. Z Psychiatr Psych Ps 2010;58:323-31.

[40] Rosler M, Retz W, Retz-Junginger P, Stieglitz RD, Kessler H, Reimherr F, et al. Attention deficit hyperactivity disorder in adults: benchmarking diagnosis using the Wender-Reimherr adult rating scale. Der Nervenarzt 2008;79:320-7.

[41] Conners CK, Erhardt D, Sparrow E. Conner's adult ADHD rating scales: technical manual: multi-health systems incorporated (MHS). 1999.

[42] Ward MF, Wender PH, Reimherr FW. The Wender Utah Rating Scale: an aid in the retrospective diagnosis of childhood attention deficit hyperactivity disorder. Am J Psychiatry 1993;150:885-90.

[43] Retz-Junginger P, Retz W, Blocher D, Weijers HG, Trott GE, Wender PH, et al. Wender Utah rating scale: the short-version for the assessment of the attention-deficit hyperactivity disorder in adults. Der Nervenarzt 2002;73:830-8.

[44] Riecher-Rössler A, Gschwandtner U, Aston J, Borgwardt S, Drewe M, Fuhr P, et al. The Basel early-detection-of-psychosis (FEPSY)-study-design and preliminary results. Acta Psychiatr Scand 2007;115:114-25.

[45] Riecher-Rössler A, Pflueger MO, Aston J, Borgwardt SJ, Brewer WJ, Gschwandtner U, et al. Efficacy of using cognitive status in predicting psychosis: a 7-year follow-up. Biol Psychiatry 2009;66:1023-30.

[46] Riecher-Rössler A, Aston J, Ventura J, Merlo M, Borgwardt S, Gschwandtner U, et al. The Basel Screening Instrument for Psychosis (BSIP): development, structure, reliability and validity. Fortschr Neurol Psychiatr 2008;76:207-16.

[47] Yung AR, Phillips LJ, McGorry PD, McFarlane CA, Francey S, Harrigan S, et al. Prediction of psychosis: a step towards indicated prevention of schizophrenia. Br J Psychiatry Suppl 1998;172:14-20.

[48] Knye M, Roth N, Westhus W, Heine A. Continuous Performance Test (CPT). Göttingen: Hogrefe; 2003.

[49] Delis DC, Kramer JH, Kaplan E, Thompkins BAO. CVLT: California Verbal Learning Test-Adult Version: Manual: Psychological Corporation. 1987.

[50] Gediga G, Schöttke H. Turm Von Hanoi-TvH. Hogrefe Testsystem (HTS) Göttingen: Hogrefe; 1994

[51] R Core Team. R: a language and environment for statistical computing. 2016.

[52] Brown AS, Vinogradov S, Kremen WS, Poole JH, Deicken RF, Penner JD, et al. Prenatal exposure to maternal infection and executive dysfunction in adult schizophrenia. Am J Psychiatry 2009;166:683-90.

[53] Freedman D, Bao Y, Kremen WS, Vinogradov S, McKeague IW, Brown AS. Birth weight and neurocognition in schizophrenia spectrum disorders. Schizophr Bull 2013:39:592-600.

[54] Payne EH, Hardin JW, Egede LE, Ramakrishnan V, Selassie A, Gebregziabher M. Approaches for dealing with various sources of overdispersion in modeling count data: scale adjustment versus modeling. Stat Methods Med Res 2015;26 (4):1802-23, doi:http://dx.doi.org/10.1177/0962280215588569.

[55] Bretz F, Hothorn T, Westfall PH. Multiple comparisons using R. Boca Raton: CRC Press; 2011.

[56] Benjamini Y, Drai D, Elmer G, Kafkafi N, Golani I. Controlling the false discovery rate in behavior genetics research. Behav Brain Res 2001;125:279-84.

[57] Strobl C, Malley J, Tutz G. An introduction to recursive partitioning: rationale, application, and characteristics of classification and regression trees, bagging, and random forests. Psychol Methods 2009:14:323-48.

[58] Fernandez-Delgado M, Cernadas E, Barro S, Amorim D. Do we need hundreds of classifiers to solve real world classification problems. J Mach Learn Res 2014:15:3133-81.

[59] Sekhon JS. Multivariate and propensity score matching software with automated balance optimization: the matching package for R. J Stat Softw 2011;42:1-52.

[60] Liaw A, Wiener M. Classification and regression by randomForest. R News 2002;2:18-22.

[61] Bischl B, Lang M, Kotthoff L, Schiffner J, Richter J, Studerus E, et al. Mlr: machine learning in R. J Mach Learn Res 2016:2016.

[62] Bora E, Lin A, Wood SJ, Yung AR, McGorry PD, Pantelis C. Cognitive deficits in youth with familial and clinical high risk to psychosis: a systematic review and meta-analysis. Acta Psychiatr Scand 2014;130:1-15.

[63] Boonstra AM, Kooij JJ, Oosterlaan J, Sergeant JA, Buitelaar JK. Does methylphenidate improve inhibition and other cognitive abilities in adults with childhood-onset ADHD. J. Clin. Exp Neuropsychol 2005;27:278-98.

[64] Faber G, Smid HG, Van Gool AR, Wiersma D, Van Den Bosch RJ. The effects of guided discontinuation of antipsychotics on neurocognition in first onset psychosis. Eur Psychiatry 2012;27:275-80. 